away, disenchanted.

Perhaps the biologists posed the most pointed question: can algebraic formulae tell us more than reasoning about the behaviour of complex biological systems? This question echoes almost half a century later, but Frank is undeterred. One day he may be seen as the pioneer who began the difficult task of building a sturdy foundation for a truly useful mathematical model of cancer development.

Robert A. Weinberg is at the Whitehead Institute for Biomedical Research, Massachusetts Institute of Technology, Cambridge, Massachusetts 02142, USA.

\title{
One-man canary
}

\section{Suffer and Survive: The Extreme Life of \\ J. S. Haldane \\ by Martin Goodman \\ Simon \& Schuster: 2007.320 pp. $£ 14.99$ \\ (Not available in the United States)}

\section{Andy Meharg}

That the nineteenth-century physician J. S. Haldane lived to his mid-70s was more down to luck than self-preservation. In his study of respiration and lung disease, Haldane performed series after series of experiments on himself, any one of which could have been fatal. In an air-tight chamber he systematically exposed himself to dangerous levels of toxic gases for extended periods to see how his body would react, his only precaution being a colleague watching through a window to see when he collapsed.

What drove Haldane was his innate scientific curiosity and a desire to save others' lives. $\mathrm{He}$ worked tirelessly to protect miners from the perils of coal dust, methane, carbon monoxide, carbon dioxide and low oxygen levels. He would rush to mine disasters to experience the fatal vapours and so determine the cause of death. He devised safety measures, such as his famed canary cage with a built-in oxygen supply to revive the bird when it collapsed. And by telling Cornish miners to spray the rock face with water as they cut, to reduce dust, he saved thousands from an early and painful death from the lung disease silicosis.

When German chemist Fritz Haber developed chemical warfare during the First World War, the British government turned to Haldane to protect the troops. There followed an arms race as Haber tried to outwit Haldane's development of gas masks. In the course of this work, Haldane frequently exposed himself to chlorine and mustard gases used on the battle- field. He conducted research on the front line to work out what gases were being used, and gauged their physiological impact by autopsying dead soldiers. He also pioneered the oxygen treatment used to recuperate soldiers who survived gas attacks.

Haldane's war effort went beyond the trenches. His work on deep-sea diving and the atmosphere in submarines saved many lives, and his studies of high altitudes benefited pilots and laid the way for the conquest of Mount Everest. It was Haldane who discovered that the body produces extra haemoglobin during acclimation to low oxygen at high altitudes.

The life of this fearless man is neatly laid out in Martin Goodman's biography Suffer and Survive. Goodman conveys Haldane's scientific dynamism and his love for life. Haldane was interested in philosophy, music and theatre, and had a fascinating family and social circle: the writer Aldous Huxley was a suitor for his daughter, for example, and novelist J. M. Barrie was a guest at his

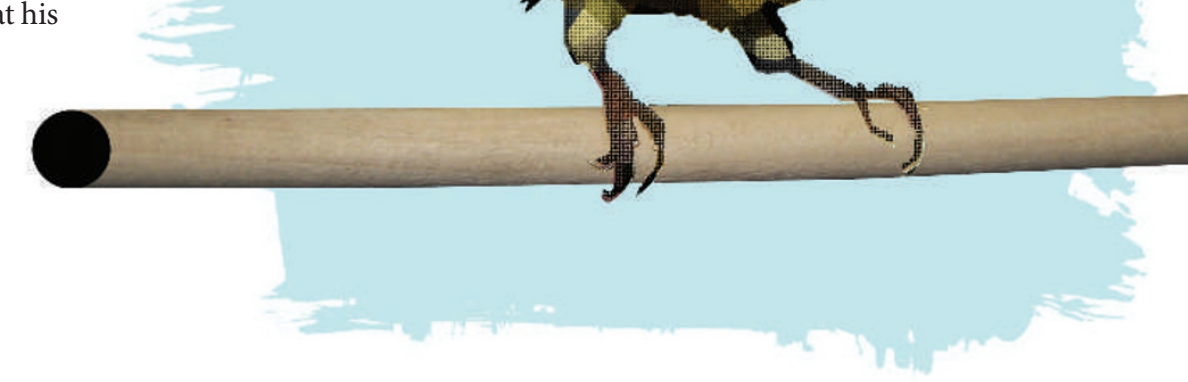

Scottish estate. In 1912, using a scientific mission as cover, Haldane accompanied his brother Richard - secretary of state for war and later the first Labour lord chancellor - to Germany for secret negotiations with the Kaiser to avert war.

This fine book is not without fault. The first chapter has vividly imagined scenes embroidered onto real events, presumably for dramatic effect, describing how Haldane rushed to a Welsh coal-mining accident. This device is thankfully used less in subsequent chapters. However, it is not until 100 pages in that descriptions of Haldane's experimental gas chamber and his measurements of carbon dioxide and carbon monoxide in blood, so central to the opening chapter, are outlined. After this shaky start, the book becomes highly enjoyable. It is a fitting tribute to a pioneer who enabled the human body to survive at the extremes of modern life.

Andy Meharg is professor of biogeochemistry at the University of Aberdeen, Cruickshank Building, St Machar Drive, Aberdeen AB24 3UU, UK, and is the author of Venomous Earth: How Arsenic Caused the World's Worst Mass Poisoning. 